\title{
Breastfeeding self-efficacy and related factors during early postpartum period
}

\author{
Senay Topuz ${ }^{1}$, Nuriye Buyukkayaci Duman ${ }^{2}$, Gulzade Uysal $^{3}$, and Dilek Ocalan ${ }^{4}$
}

\section{ABSTRACT}

\section{BACKGROUND}

Breastfeeding self-efficacy (BSE) could be an indicator of the performance of mothers in breastfeeding during the immediate postpartum time period. The factor most affecting the duration and success of breastfeeding is the self-efficacy perception of the mothers. This study was carried out to determine the BSE and the factors related to it in the early postpartum period.

\section{METHODS}

A cross-sectional study was performed involving 264 mothers. Data were collected by using a questionnaire and the BSE scale (BSES). The questionnaire consisted of questions regarding descriptive characteristics (age, educational status, family type, income level, etc.) and obstetric characteristics regarding pregnancy, delivery and breastfeeding status (number of pregnancies, number of births, type of delivery, planned and desired pregnancy, birth weight, first breast-feeding time after birth, etc.). Simple and multiple linear regression were performed to examine factors related to BSE.

\section{RESULTS}

The mean BSE score of the mothers participating in the study was $65.20 \pm$ 9.3. Simple and multiple linear regression models indicated that significant determinants of BSE score include having nuclear family type, having social security, a greater number of pregnancies, a greater number of births, the status of antenatal visits in pregnancy, the status of getting information about breastfeeding, and short first breastfeeding time. Getting information about breastfeeding was the most influential factor of BSE (Beta=3.432; $95 \% \mathrm{CI}: 32.771-51.626 ; \mathrm{p}=0.000)$.

\section{CONCLUSIONS}

In this study, getting information about breastfeeding was the most influential factor of BSE in the early postpartum period. Awoman's level of breastfeeding self-efficacy should be determined during the early postpartum period.

Keywords: Breastfeeding, self-efficacy, early postpartum period
${ }^{1}$ Ankara University, Faculty of Health Sciences, Department of Midwifery, Ankara, Turkey

${ }^{2}$ Hitit University, Faculty of Health Sciences, Department of Nursing, Çorum, Turkey

${ }^{3}$ Okan University, Faculty of Health Sciences, Department of Nursing, Istanbul, Turkey

${ }^{4}$ Afyonkarahisar University of Health Sciences, Faculty of Health Sciences, Department of Nursing, Afyonkarahisar, Turkey

\section{Correspondence:}

Nuriye Buyukkayaci Duman Hitit University,

Faculty of Health Sciences, Department of Nursing, Corum, Turkey, TR 19100 Phone: +905055015752 email: nurfatihh@hotmail.com ORCID ID: 0000-0002-4246-3607

Date of first submission, March 9, 2021

Date of final revised submission, October 31, 2021

Date of acceptance, November 10 , 2021

This open access article is distributed under a Creative Commons AttributionNon Commercial-Share Alike 4.0 International License

Cite this article as: Topuz S, Duman NB, Uysal G, Ocalan D. Breastfeeding selfefficacy and related factors during early postpartum period. Univ Med 2021;40: 216-25. doi: 10.18051/UnivMed.2021. v40.216-225. 


\section{INTRODUCTION}

Breast milk is the most important and main source of food for the baby, and breastfeeding is the best type of feeding. The World Health Organization and the United Nations International Children's Emergency Fund recommend to feed babies only with breast milk within the first 6 months after birth (exclusive breastfeeding), and besides, the Innocenti declaration emphasizes that the breastfeeding period should be two years or even more. ${ }^{(1,2)}$ However, it was found that the rates of breastfeeding are high in Turkey but the rates of exclusive breastfeeding (giving only breast milk) within the first six months are low. ${ }^{(3)}$ While the rate of breastfeeding in the first hour after birth in Turkey is $71 \%$, the rate of breastfeeding within the first day after birth is $86 \%$, while the rate of giving infant formula before breastfeeding is $42 \%{ }^{(3)}$

It is well known that starting and continuing breastfeeding and exclusive breastfeeding within the first six months are affected by many factors. ${ }^{(4-6)}$ In many studies evaluating the factors affecting breastfeeding, it was emphasized that the factor most affecting the duration and success of breastfeeding was the self-efficacy perception of the mothers. ${ }^{(4-6)}$ According to the breastfeeding self-efficacy (BSE) theory that was developed by Dennis, ${ }^{(7)}$ mothers who have a high selfefficacy prefer breastfeeding, behave more positively when faced with difficulties and try to solve the problems by thinking positively. Dennis (7) defined the perception of BSE as "mother's feeling of self-efficacy for breastfeeding" and emphasized that mothers with a high self-efficacy for breastfeeding could cope with the difficulties during the breastfeeding period more strongly and that mothers with a low self-efficacy left breastfeeding earlier. It was stated that the breastfeeding success of the mothers, whose BSE was low, was low and that the mother could not continue breastfeeding. ${ }^{(7,8)}$ Studies on the subject show that mothers with high breastfeeding selfefficacy have higher breastfeeding success and breastfeed their babies for a longer period of time. ${ }^{(9-12)}$ Mother's age, educational and income levels, family structure, status of desiring pregnancy and experiencing health problems during pregnancy, previous experiences regarding breastfeeding, employment status, type of delivery, starting time for breastfeeding, mother's feeling that her breast milk is insufficient and support from the spouse can be counted as other factors that affect BSE. ${ }^{(9-12)}$

When the literature is examined, different research results are found on the factors affecting mothers' BSE. In the studies of Dodt et al. ${ }^{(13)}$ it was determined that as the age of the mother increased, the mean BSE score also increased. In the same study, it was determined that the mother's educational level, profession, marital status, income level and number of pregnancies did not affect breastfeeding self-efficacy. In the studies of Glassman et al., ${ }^{(14)}$ it was reported that there is a positive relationship between high educational level, breastfeeding for more than 6 months, exclusive breastfeeding and BSE. In the studies of Yang et al., ${ }^{(15)}$ no relationship was found between socio-demographic and perinatal characteristics such as age, educational level, occupation, monthly income level, time of decision to breastfeed, mode of delivery and BSE score averages. It has been determined that multiparity and participation in breastfeeding education classes have a positive effect on BSE. In the studies of Zhu et al., ${ }^{(16)}$ it was reported that mothers who had breastfeeding experience had higher BSE. In the studies of Cantürk and Kostak ${ }^{(17)}$ and of Akkoyun and Arslan, ${ }^{(18)}$ it was reported that as age, number of pregnancies and number of living children increased, the BSE of mothers increased, while in the studies of Yol and Tezel, ${ }^{(19)}$ the BSE of multiparous mothers was higher than that of primiparous mothers, but age did not affect BSE. In the studies of Akkoyun and Arslan, ${ }^{(18)}$ Fata and Ustun Akan, ${ }^{(20)}$ and Canturk and Kostak, ${ }^{(17)}$ it was determined that there is a positive relationship between educational level and BSE. In the studies of Uludad ${ }^{(21)}$ and Comert and Ege, ${ }^{(22)}$ it was reported that family type did not affect the BSE of mothers, while in the studies of 
Yol and Tezel, ${ }^{(19)}$ and Cantürk and Kostak ${ }^{(17)}$, it was reported that the BSE of those with a nuclear family structure was high. In the studies of Bolat et al, ${ }^{(23)}$ Küçükoðlu et al., ${ }^{(24)}$ Cömert and Ege, ${ }^{(22)}$ as well as of Cantürk and Kostak, ${ }^{(17)}$ it was determined that mothers with social security and medium and high income levels had higher BSE. In the studies of Akkoyun and Arslan, ${ }^{(18)}$ it was reported that income status did not affect BSE. There are different study results regarding the relationship of experiencing problems during pregnancy and BSE of mothers. In some studies it was reported that mothers who did not have problems during pregnancy had higher BSE and that having problems during pregnancy affected BSE negatively ${ }^{(17,25)}$ while in other studies no relationship was found. ${ }^{(22)}$ According to the literature, one of the factors affecting BSE is early skin-to-skin contact and breastfeeding within the first 30 minutes after birth. Studies on the subject show that mothers who feed their babies with breast milk (colostrum) within the first 30 minutes have higher BSE. ${ }^{25-28)}$

When the literature is examined, it is seen that there are many studies on breastfeeding status of infants and breastfeeding, but the results are still inconsistent. This situation was the determining factor in the planning of our study. This study was carried out to determine the BSE and its predictors in the early postpartum period.

\section{METHODS}

\section{Research design}

A cross-sectional study was performed between May 2017-May 2018 in Kirikkale University Medical Faculty Hospital.

\section{Research subjects}

The universe of the study was composed of all mothers who delivered a baby in Kirikkale University Medical Faculty Hospital. The sample size of the study was based on the total score of breastfeeding self-efficacy scale of $68.08 \pm 14.48$ in the study of Konukodlu and Pasinliodlu ${ }^{(29)}$ using the 2019 Statistics, Graphics, Power Analysis \&
Sample Size( NCSS-PASS) program (type I error 0.05 , type II error 0.20 ), such that the sample was composed of 264 mothers who were eligible according to the inclusion criteria and were approved to participate in the study.

Included in this study were women 18 years of age or older, who had a single birth at term (38-42 weeks), had a healthy newborn (birth weight of 2500-4000 g, no congenital disease, no history of hospitalization in the neonatal intensive care unit), had no chronic disease that prevented breastfeeding, and breastfeeding women who did not have communication problems.

\section{Data collection}

Mothers who delivered a baby were given a face-to-face questionnaire and the BSE scale. The questionnaire was prepared by the researchers based on the literature and the BSE scale, and consisted of questions regarding descriptive characteristics of the mothers (age, educational status, family type, income level, having social security) and their obstetric characteristics regarding pregnancy, delivery and breastfeeding status (number of pregnancies, number of births, type of delivery, planned and desired pregnancy, birth weight, first breastfeeding time after birth, getting information about breastfeeding, etc.).

The content of the questionnaire form, operability and clarity of the questions were evaluated by taking an expert opinion; and some revisions were made in the questionnaire form in accordance with the opinions and suggestions of the expert.

\section{Breastfeeding self-efficacy scale (BSES)}

This is a scale comprising 33 items that was developed by Dennis and Faux ${ }^{(8)}$ in order to measure beliefs and thoughts regarding breastfeeding and breastfeeding efficacy of the mothers. A validity and reliability study of the Turkish version of the scale was conducted by Eksioglu and Ceber. ${ }^{(30)}$ Breastfeeding efficacies of the mothers were evaluated based on a 5-point Likert scale. The items were scored as (1) I never 
trust myself, (2) I do not trust myself very much, (3) I sometimes trust myself, (4) I trust myself most of the time, (5) I always trust myself. The lowest score is 14 , and the highest score is $70 .^{(8)}$ As the score obtained from the scale increases, breastfeeding self-efficacy also increases. The average application time of the scale takes 10-15 minutes. ${ }^{(8)}$

\section{Statistical Analysis}

The data were evaluated using the Statistical Package for the Social Sciences (SPSS) program version 20.0. Descriptive statistics were shown with number (n), percentage (\%) and mean \pm standard deviation in the analysis of the data. Simple linear regression analysis was used to find associations between the independent variables and the BSE. All variables showing a significant association in the bivariate analysis at $\mathrm{p}<0.25$ were entered into a multivariate linear regression model to determine the risk factors associated with the BSE. The results were evaluated at $95.0 \%$ confidence interval, $\mathrm{p}<0.05$ significance level.

\section{Ethical Consent}

Ethical approval was obtained from local clinical research ethics committee Kirikkale University (15/12/2015-28-4). All participants provided written informed consent.

\section{RESULTS}

The mean age of the women was $28.39 \pm$ 5.82 years and approximately half of them were between the ages of $26-35$ years; $41.1 \%$ were high school graduates, $82.5 \%$ had a nuclear family structure, $78 \%$ had middle income and $90.2 \%$ had social security (Table 1).

It was determined that $42.7 \%$ of the women participating in the study had their first pregnancy and $52.8 \%$ had their first birth. The majority of women $(87.4 \%)$ had planned and desired the pregnancy and $72.8 \%$ stated that they did not have any health problems during pregnancy. Furthermore, 94.3\% stated that they regularly
Table 1. Distribution of the mothers according to their sociodemographic characteristics $(n=246)$

\begin{tabular}{lc}
\hline Characteristics & $\mathbf{n}(\mathbf{\%})$ \\
\hline Age*(years) & $28.39 \pm 5.82$ \\
18-25 & $90(36.6)$ \\
$26-35$ & $129(52.4)$ \\
36 years and over & $27(11.0)$ \\
Educational status & \\
Primary school & $15(6.1)$ \\
High school & $101(41.1)$ \\
University & $95(38.6)$ \\
Master Degree & $35(14.2)$ \\
Family type & \\
Nuclear family & $203(82.5)$ \\
Extended family & $43(17.5)$ \\
Income level & \\
High & $28(11.4)$ \\
Middle & $192(78.0)$ \\
Low & $26(10.6)$ \\
Having social security & \\
Yes & $222(90.2)$ \\
No & $24(9.8)$ \\
\hline
\end{tabular}

$*$ Mean $\pm \mathrm{SD}$

went to antenatal visits and $54.9 \%$ of the women gave birth by cesarean. When the birth weight of the babies was examined, $83.7 \%$ of the babies weighed $2500-4000 \mathrm{~g}$. It was determined that $58.9 \%$ of women breastfed their babies within $30-60$ minutes following birth. While $56.1 \%$ of women stated that they received information about breastfeeding during pregnancy, $84.1 \%$ stated that it is necessary to give information to mothers about breastfeeding during pregnancy (Table 2). The mean BSE score of the mothers participating in the study was $65.20 \pm 9.3$. In view of this score average, it can be said that the mean BSES score of the mothers participating in the study was high (Table 2).

The simple and multiple linear regression models indicated that significant determinants of BSE score include increased educational status, having nuclear family type, having social security, a greater number of pregnancies, a greater number of births, the status of antenatal visits in pregnancy, the status of getting information about breastfeeding, short first breastfeeding time and no health problems in pregnancy. The most 
Table 2 . Distribution of the mothers according to pregnancy-related features, history of births, and the BSE score

\begin{tabular}{|c|c|}
\hline Characteristics & n (\%) \\
\hline \multicolumn{2}{|l|}{ Number of pregnancies } \\
\hline 1 & $105(42.7)$ \\
\hline 2 & $72(29.3)$ \\
\hline 3 & $52(21.1)$ \\
\hline 4 and over & $17(6.9)$ \\
\hline \multicolumn{2}{|l|}{ Number of births } \\
\hline 1 & $130(52.8)$ \\
\hline 2 & $55(22.4)$ \\
\hline 3 & $50(20.3)$ \\
\hline 4 and over & $11(4.5)$ \\
\hline \multicolumn{2}{|l|}{ Type of delivery } \\
\hline Vaginal & $111(45.1)$ \\
\hline Cesarean & $135(54.9)$ \\
\hline \multicolumn{2}{|l|}{ Planned and desired pregnancy } \\
\hline Yes & $215(87.4)$ \\
\hline No & $31(12.6)$ \\
\hline \multicolumn{2}{|l|}{$\begin{array}{l}\text { Having a health problem in } \\
\text { pregnancy }\end{array}$} \\
\hline Yes & $67(27.2)$ \\
\hline No & $179(72.8)$ \\
\hline \multicolumn{2}{|l|}{$\begin{array}{l}\text { The status of antenatal visits in } \\
\text { pregnancy }\end{array}$} \\
\hline Yes & $232(94.3)$ \\
\hline No & $14(5.7)$ \\
\hline \multicolumn{2}{|l|}{ Birth weight (grams) } \\
\hline Under 2500 & $19(7.7)$ \\
\hline $2500-4000$ & $206(83.7)$ \\
\hline 4000 and over & $21(8.5)$ \\
\hline \multicolumn{2}{|l|}{$\begin{array}{l}\text { First breast-feeding time after } \\
\text { birth }\end{array}$} \\
\hline Within the first $30-60$ minutes & $145(58.9)$ \\
\hline 2-3 hours & $42(17.1)$ \\
\hline 1 day & $24(9.8)$ \\
\hline 2 days and over & $35(14,2)$ \\
\hline \multicolumn{2}{|l|}{$\begin{array}{l}\text { Getting information about } \\
\text { breastfeeding }\end{array}$} \\
\hline Yes & $138(56.1)$ \\
\hline No & $108(43.9)$ \\
\hline \multicolumn{2}{|l|}{$\begin{array}{l}\text { Thinking that mothers need to be } \\
\text { informed during pregnancy }\end{array}$} \\
\hline Yes & $207(84.1)$ \\
\hline No & $39(15.9)$ \\
\hline BSE Score* & $65.20 \pm 9.3$ \\
\hline
\end{tabular}

influential determinant factor of BSE was the status of getting information about breastfeeding $($ Beta $=3.432 ; 95 \%$ C.I.: 32.771- 51.626; $\mathrm{p}=0.000)$ (Table 3).

\section{DISCUSSION}

The breastfeeding self-efficacy scale mean score of the mothers in the study was found to be $65.20 \pm 9.3$. Based on this mean score, it can be said that the BSE of the mothers participating in the study was high. When the studies on the subject were examined, different research results were found. Unlike the results of our study, mothers' BSES mean scores were found to be low in some studies. ${ }^{(24,31)}$ In the studies of Faridvand et al., ${ }^{(9)}$ Yenal et al. ${ }^{(32)}$ and Akkoyun and Arslan ${ }^{(18)}$, mothers' BSES mean scores were found to be lower, namely $59.18 \pm 9.56,59.49 \pm$ 8.46 , and $59.18 \pm 9.46$, respectively. The finding of our study differs from the results of the aforementioned studies. This difference may have been due to the fact that our sample group has different sociodemographic and obstetric characteristics from living in a different region.

According to the literature, mothers' BSE, age, socio-cultural level, economic status, having health insurance, access to health services, number of pregnancies and births, mode of delivery, past breastfeeding experience, breastfeeding education, preparation for pregnancy and participation in prenatal education classes, are affected by many factors such as the condition of pregnancy or the status of having problems during pregnancy. ${ }^{(31,33,34)}$ Similarly, in our study, significant determinants of BSES include increased educational status, having nuclear family type, having social security, a greater number of pregnancies, a greater number of births, the status of antenatal visits in pregnancy, the status of getting information about breastfeeding, short first breastfeeding time and no health problems in pregnancy.

In our study, the status of getting information about breastfeeding (Beta $=3.432$ ) was the most influential determinant factor of BSE (Table 3 ). It was also observed that mean BSES scores of the mothers who got information about breastfeeding during pregnancy and thought that it was necessary, were higher than that of the ones who did not. Similar to the results of our 
Table 3. Results of simple and multiple linear regression for predicting breastfeeding self-efficacy in postpartum women $(n=246)$

\begin{tabular}{lccccccc}
\hline \multirow{2}{*}{ Characteristics } & \multicolumn{3}{c}{ Simple Linear Regression } & \multicolumn{3}{c}{ Multiple Linear Regression } \\
\cline { 2 - 7 } & $\boldsymbol{\beta}$ & $\mathbf{9 5} \%$ C.I & p value & Beta & $\mathbf{9 5} \%$ C.I & p value \\
\hline Age (years) & 0.296 & $(0.977-1.945)$ & 0.494 & - & - & - \\
Educational status & 1.324 & $(2.357-4.393)$ & $0.000^{*}$ & 1.673 & $(3.412-5.221)$ & $0.000^{*}$ \\
Nuclear family type & 1.287 & $(7.234-12.432)$ & $0.000^{*}$ & 1.778 & $(6.810-16.220)$ & $0.000^{*}$ \\
Income level & 0.312 & $(0.418-1.324)$ & 0.381 & - & - & - \\
Having social security & 0.820 & $(2.435: 5.348)$ & $0.000^{*}$ & 1.118 & $(3.170-6.857)$ & $0.000^{*}$ \\
Number of pregnancy & 1.673 & $(0.0005-0.003)$ & $0.000^{*}$ & 1.431 & $(0.0003-1.009)$ & $0.000^{*}$ \\
Number of births & 1.433 & $(6.255-10.278)$ & $0.000^{*}$ & 1.345 & $(5.149-8.530)$ & $0.000^{*}$ \\
$\begin{array}{l}\text { Planned and desired } \\
\text { pregnancy }\end{array}$ & 0.334 & $(0.689-2.346)$ & 0.392 & - & - & - \\
$\begin{array}{l}\text { Type of delivery } \\
\text { The status of having no }\end{array}$ & 0.128 & $(0.578-1.345)$ & 0.421 & - & & - \\
health problem in pregnancy & 1.478 & $(7.675-12.238)$ & $0.000^{*}$ & 1.562 & $(7.443-13.338)$ & $0.000^{*}$ \\
$\begin{array}{l}\text { The status of antenatal visits } \\
\text { in pregnancy }\end{array}$ & 1.423 & $(0.444-0.620)$ & $0.000^{*}$ & 1.423 & $(0.656-0.778)$ & $0.000^{*}$ \\
$\begin{array}{l}\text { Birth weight (grams) } \\
\text { First breast-feeding time after } \\
\text { birth }\end{array}$ & 0.446 & $(0.542-1.978)$ & 0.296 & - & - & - \\
$\begin{array}{l}\text { Getting information about } \\
\text { breastfeeding }\end{array}$ & 2.487 & $(18.345-32.123)$ & $0.000^{*}$ & 2.546 & $(16.232-28.223)$ & $0.000^{*}$ \\
\hline
\end{tabular}

B: regression coeffficient; Beta: standardized regression coefficient

study, some studies have reported that the status of getting information about breastfeeding or breastfeeding education positively affects BSE. ${ }^{(14-}$ ${ }^{17)}$ In support of the outcome of our study, RossCowdery et al. ${ }^{(35)}$ emphasized in their study that breastfeeding training given during pregnancy was very important in early breastfeeding and in providing the continuity of breastfeeding. McCoy et al. ${ }^{(36)}$ also detected that training that was based on BSE theory was very effective in improving self-efficacy perception and success of breastfeeding. On the contrary, Yilmaz et al. ${ }^{(37)}$ found the rate of exclusive breastfeeding within the first 6 months to be $33.3 \%$ in the group which had training during pregnancy and $37.5 \%$ in the control group.

In our study, it was found that regular checkups during pregnancy and not having any health problems during pregnancy were associated with high BSE. Similarly, it was seen that mean BSE scores of the mothers who did not experience any problems during pregnancy was higher than that of the mothers who had problems. Going to antenatal visits regularly during pregnancy and getting consultations on breastfeeding are important since this increases the success of breastfeeding and provides early detection and resolution of possible problems. ${ }^{\left({ }^{(35,36)}\right.}$ Completion of this period without having problems can affect the success of breastfeeding since it enables the women to enter the postpartum period with less stress. The results of our study support these outcomes.

In the studies of Faridvand et al..$^{(9)}$ and Yol and Tezel, ${ }^{(19)}$ no relationship was found between the age of the mothers and the mean BSES scores, whereas the mean BSES scores of multiparous mothers were higher than those of primiparous mothers. In the studies of Cantürk and Akgun Kostak, ${ }^{(17)}$ it was reported that as the age of the mothers, the number of pregnancies and the number of children increased, the BSE levels also increased. In the studies of Yang et al., ${ }^{(15)}$ while no relationship was found between other socio-demographic and perinatal characteristics such as age, educational level, 
occupation, monthly income level, time of decision to breastfeed, mode of delivery and the mean BSE scale scores, it was found that multiparity and participation in breastfeeding education classes had a positive effect on BSE. ${ }^{(15)}$ In the studies of Zhu et al., ${ }^{(16)}$ it was reported that mothers who had breastfeeding experience had higher BSE. In the study by Muelbert and Giugliani (38) evaluating the factors that cause breastfeeding to continue for 6,12 and 24 months in adolescent mothers, it was determined that adolescent mothers had more negative behaviors and attitudes compared to the adult mothers regarding breastfeeding; and they required more information and help. The reason of the decrease in mean BSE score as age decreased in our study may be the high incidence of early age marriages and the presence of a strong family support in the marriages. ${ }^{(39)}$ According to the results of the study, the increase in BSE with the number of pregnancies and births, regardless of the age of the mothers, can be explained by the mothers having knowledge and experience about breastfeeding.

Educational level is an important factor that increases awareness of breastfeeding. The rates of breastfeeding are expected to be higher among the mothers as educational level increases. ${ }^{(38-41)}$ The findings of our study agree with the results of these prior studies.

Family type is also one of the factors affecting the success of breastfeeding ${ }^{(38,42)}$ Also in our study, it was detected that mean BSE scores of the mothers who were living in a core family were higher than those of the ones who were living in a large family, the difference being statistically significant. Similar to the results of our study, in the study by Faridvand et al. ${ }^{(9)}$ it was reported that mean BSE scores of the mothers who were living in a core family were higher than the ones who were living in a large family and a statistically significant difference was found between both groups.

The fact that pregnancy is planned and desired is one of the factors affecting breastfeeding behavior. ${ }^{(42-44)}$ In our study, it was determined that planned and voluntary pregnancy did not affect mothers' BSE. Similarly, in the studies of Faridvand et al. ${ }^{(9)}$, the relationship between planned desired pregnancy and the BSE mean scores was found to be statistically insignificant.

According to the literature, it is reported that the situation of having problems during pregnancy may affect the BSE of mothers. ${ }^{(17,22)}$ Similarly, in our study, it was determined that as the mothers.

In the literature, the type of delivery has been reported to constitute one of the factors problems in pregnancy increased, the BSES mean scores decreased. When the studies on the subject were examined, it was determined that Comert and Ege's ${ }^{(22)}$ study did not affect the status of having health problems during pregnancy and the BSES mean scores. Supporting the results of our study, it was reported that mothers who had an uneventful pregnancy had high BSE levels in the studies of Cantürk and Kostak. ${ }^{(17)}$ affecting the success of breastfeeding and beginning and duration of breastfeeding. ${ }^{(42,45)}$ When the studies on the subject are examined, it is reported that cesarean delivery negatively affects the mean starting breastfeeding, continuing breastfeeding and total breastfeeding times. ${ }^{(22,23)}$ In our study, it was determined that the mode of delivery did not affect the BSE of the mothers. Similarly, in the studies of Cantürk and Akgün Kostak, ${ }^{(17)}$ Alup Tokat et al., ${ }^{(28)}$ Cömert and Ege, ${ }^{(22)}$ Gokbulut, ${ }^{(25)}$ Akkoyun and Arslan ${ }^{(18)}$ Yol and Tezel ${ }^{(19)}$ and Uludad, ${ }^{(21)}$ no relationship was found between the mode of delivery and the mothers' BSES mean scores. In our study, it is thought that the mode of delivery does not affect breastfeeding proficiency, since most of the mothers breastfeed their babies in the first hour regardless of the mode of delivery.

The characteristics of the newborn such as birth weight are also among the factors affecting success of breastfeeding. ${ }^{(46,47)}$ It is an expected situation that mothers of the newborns who have a low birth weight experience problems with cuddling the baby and with the breastfeeding position. The same problems may be experienced by the mothers of newborns who have a birth 
weight above normal. ${ }^{(46,47)}$ Differently, in our study, it was determined that birth weight did not relate to maternal BSE. This can be explained by the fact that the majority of the babies $(83.7 \%)$ included in the sample were of normal birth weight.

Because this study was limited to the BSE of mothers in a university hospital in Kýrýkkale province, the results can only be generalized to this group. For this reason, the numerical smallness of the sample size in the study and the homogeneous distribution of the sociodemographic characteristics of the mothers can be considered as the limitations of the study. Based on the results of the study, it is thought that the standard evaluation of mothers' BSE and the affecting factors in the postpartum period and the determination of breastfeeding counseling needs can positively affect mothers' BSE and breastfeeding success.

\section{CONCLUSION}

In this study, the status of getting information about breastfeeding was the most influential determinant factor of BSE after analysis of the standardized regression coefficient (Beta). It is suggested that further studies to be conducted on the subject should be planned as cohort studies.

\section{CONFLICTS OF INTEREST}

There are no conflicts of interest.

\section{ACKNOWLEDGMENT}

We thank the mothers in the postpartum period who supported the study by accepting to participate in the study.

\section{CONTRIBUTORS}

ST, NBD, and GU designed this study. ST and NBD carried out the data analyses and reported the initial findings. ST, NBD, and DO contributed to the manuscript preparation and submission. All authors have read and approved the final manuscript.

\section{REFERENCES}

1. World Health Organization. World Health Organization Guideline: protecting, promoting and supporting breastfeeding in facilities providing maternity and newborn services. Geneva: World Health Organization; 2017.

2. Arts M, Taqi I, Begin F. Improving the early initiation of breastfeeding: the WHO-UNICEF Breastfeeding Advocacy Initiative. Breastfeed Med 2017;12:326-7. doi: 10.1089/bfm.2017.0047.

3. Hacettepe Universitesi Nufus Etutleri Enstitusu (HUNEE), TC Kalkynma Bakanlydy, Tübitak. 2018 Turkiye Nufus ve Sadlyk Arastyrmasy. Hacettepe Universitesi Nufus Etütleri Enstitusu, Ankara; 2018.

4. De Roza JG, Fong MK, Ang BL, Sadon RB, Koh EYL, Teo SSH. Exclusive breastfeeding, breastfeeding self-efficacy and perception of milk supply among mothers in Singapore: a longitudinal study. Midwifery 2019;79:102532. doi: 10.1016/j.midw.2019.102532.

5. Efrat MW. Breastfeeding self-efficacy and level of acculturation among low-income pregnant latinas. Int J Child Health Nutrition 2018;7:16974. doi:10.6000/1929-4247.2018.07.04.6.

6. Joshi A, Amadi C, Meza J, Aguire T, Wilhelm S. Evaluation of a computer-based bilingual breastfeeding educational program on breastfeeding knowledge, self-efficacy and intent to breastfeed among rural Hispanic women. Int $\mathrm{J}$ Med Inform 2016;91:10-9. doi: 10.1016/ j.jimedinf.2016.04.001.

7. Dennis CL. Theoretical underpinnings of breastfeeding confidence: a self-efficacy framework. J Hum Lact 1999;15:195-01. doi:10.1177/089033449901500303.

8. Dennis CL, Heaman M, Mossman M. Psychometric testing of the breastfeeding selfefficacy scale-short form among adolescents. J Adolesc Health 2011;49:265-71. doi: 10.1016/j. jadohealth.2010.12.015.

9. Faridvand F, Mirghafourvand M, Malakouti J, Mohammad-Alizadeh-Charandabi S. Relationship between social support and breastfeeding selfefficacy among women in Tabriz, Iran. Br J Midwifery 2017;25:104-9. doi: 10.12968/ bjom.2017.25.2.103.

10. Kitano N, Nomura K, Kido M, et al. Combined effects of maternal age and parity on successful 
initiation of exclusive breastfeeding. Prev Med Rep 2015:121-6. doi: 10.1016/j.pmedr.2015.12.010.

11. Thet MM, Khaing EE, Diamond-Smith N, Sudhinaraset M, Oo S, Aung T. Barriers to exclusive breastfeeding in the Ayeyarwaddy region in Myanmar: qualitative findings from mothers, grandmothers, and husbands. Appetite 2016;96:62-9. doi: 10.1016/j.appet.2015.08.044.

12. Topal S, Yuvacy HU, Erkorkmaz U, Cynar N, Altýnkaynak S. The determination of infant feeding attitudes among Turkish mothers using the Iowa infant feeding attitude. Scale J Pak Med Assoc 2017;67:1567-73.

13. Dodt RCM, Ximenes LB, Almeida PC, Oria MOB, Dennis CL. Psychometric and maternal sociodemographic assessment of the breastfeeding self-efficacy scale-short form in a brazilian sample. J Nurs Educ Pract 2012;3: 66-73. doi:10.5430/jnep.v2n3p6.

14. Glassman ME, McKearney K, Saslaw M, Sirota DR. Impact of breastfeeding self-efficacy and sociocultural factors on early breastfeeding in an urban, predominantly Dominican community. Breastfeed Med 2014;9:301-7. doi: 10.1089/bfm.2014.0015.

15. Yang X, Gao LL, Ip WY, Chan WCS. Predictors of breast feeding self-efficacy in the immediate postpartum period: a cross-sectional study. Midwifery 2016;41:1-8. doi: 10.1016/ j.midw.2016.07.011.

16. Zhu J, Chan WCS, Zhou X, Ye B, He HG. Predictors of breast feeding self-efficacy among Chinese mothers: a cross-sectional questionnaire survey. Midwifery 2014;30:705-11. doi: 10.1016/ j.midw.2016.07.011.

17. Cantürk D, Kostak MA. First breastfeeding behaviors, breastfeeding self-efficacy levels and influencing factors of mothers who had vaginal delivery and cesarean section. Mersin Universitesi Sadlyk Bilimleri Dergisi 2020;13:382-94. doi: 10.26559/mersinsbd.718662.

18. Akkoyun S, Arslan FA. Breastfeeding self-efficacy of breastfeeding mothers during the first six months. J Pediatr Res 2016;3:191-5. doi:10.4274/ jpr.50469.

19. Yol E, Tezel A. Evaluation of breastfeeding selfefficacy and breastfeeding success of mothers whose babies were diagnosed with indirect hyperbilirubinemia. Yuksek lisans Tezi. Ankara (Turkey): Ankara Üniversitesi Sadlyk Bilimleri Enstitusu; 2017.

20. Fata S, Ustun Atan S. The effect of maternal fatigue on breastfeeding self-efficacy in the postpartum period. Yuksek Lisans Tezi. Izmir (Turkey): Ege Universitesi Sadlyk Bilimleri Enstitusu; 2014.
21. Uludad E. The effect of spousal support on breastfeeding self-efficacy in the postpartum period. Yüksek lisans Tezi. Erzurum (Turkey): Atatürk Universitesi Sadlyk Bilimleri Enstitusu; 2017.

22. Comert AG, Ege E. Determination of breastfeeding self-efficacy and associated factors in the postpartum period. Yuksek lisans tezi. Konya (Turkey): Selcuk Universitesi Sadlyk Bilimleri Enstitusu; 2011.

23. Bolat E, Bestas A, Bayar MK, Ozcan S, Erhan OL, Ustundag B. Evaluation of levobupivacaine passage to breast milk following epidural anesthesia for cesarean delivery. Int J Obstet Anesth 2014;23:217-21. doi: 10.1016/j.ijoa.2014. 03.005 .

24. Kucukodlu S, Celebiodlu A, Coskun D. Determination of postpartum depression symptoms and breastfeeding self-efficacy levels of mothers whose babies were hospitalized in the neonatal clinic. Gumushane Universitesi Sadlyk Bilimleri Dergisi 2014;3:921-32.

25. Gokbulut N. The effect of women's satisfaction with birth on breastfeeding self-efficacy. Yuksek lisans tezi, Okan Universitesi Sadlyk Bilimleri Enstitusu, Istanbul, 2015.

26. Koskinen KS, Aho AL, Hannula L, Kaunonen M. Maternity hospital practices and breastfeeding self-efficacy in Finnish primiparous and multiparous women during the immediate post-partum period. Midwifery 2014;30:464-70. doi:10.1016/ j.midw.2013.05.003.

27. Schafer R, Genna CW. Physiologic breastfeeding: a contemporary approach to breastfeeding initiation. J Midwifery Womens Health 2015;60: 546-53. doi:10.1111/jmwh.12319.

28. Alus Tokat M, Sercekus P, Yenal K, Okumup H. Early postpartum breastfeeding outcomes and breastfeeding self efficacy in turkish mothers undergoing vaginal birth or cesarean birth with different types of anesthesia. Int J Nurs Knowl 2015;26:73-9. doi: 10.1111/2047-3095.12037.

29. Konukodlu T, Pasinliodlu T. Determination of breastfeeding self-efficacy and influencing factors in pregnant women. J Midwifery Health Sci 2021;4:12-22.

30. Eksioglu AB, Ceber E. Translation and validation of the breast-feeding self-efficacy scale into Turkish. Midwifery 2011;27:e246-e53. doi:10.1016/ j.midw.2010.10.009

31. Kucukodlu S, Celebiodlu A. Updating breastfeeding self-efficacy level and breastfeeding success of mothers of sick newborns. Erciyes Universitesi Sadlyk Bilimleri Fakültesi Dergisi 2014;2:1-11. 
32. Yenal K, Tokat MA, Ozan YD, Cece O, Abalyn FB. Investigation of the relationship between mothers' perceptions of breastfeeding selfefficacy and breastfeeding success. Hempirelikte Eðitim ve Arabtýrma Dergisi 2013;10:14-19.

33. Gerçek E, Sarykaya Karabudak S, Ardyc Celik N, Saruhan A. The relationship between breastfeeding self efficacy and LATCH scores and affecting factors. J Clin Nurs 2017;26:9941004. doi:10.1111/jocn.13423.

34. Ynce T, Aktas G, Aktape N, Aydyn A. Evaluation of mothers' breastfeeding self-efficacy and characteristics affecting breastfeeding success. J Dr. Behcet Uz Children's Hospital 2017;7:18390. doi:10.5222/buchd.2017.183.

35. Ross-Cowdery M, Lewis CA, Papic M, Corbelli J, Schwarz EB. Counseling about the maternal health benefits of breastfeeding and mothers' intentions to breastfeed. Matern Child Health J 2017;21:23441. doi: 10.1007/s10995-016-2130-x.

36. McCoy MB, Geppert J, Dech L, Richardson M. Associations between peer counseling and breastfeeding initiation and duration: an analysis of Minnesota participants in the Special Supplemental Nutrition Program for Women, Infants, and Children (WIC). Mater Child Health J 2018;22:71-81. doi: 10.1007/s10995-017-2356-2.

37. Yýlmaz M, Ongan D, Kaya NY, et al. The effect of breastfeeding education given during pregnancy on breastfeeding and breastfeeding behaviors. Beslenme ve Diyet Dergisi 2012;40:2-11.

38. Muelbert M, Giugliani ER. Factors associated with the maintenance of breastfeeding for 6,12 , and 24 months in adolescent mothers. BMC Public Health 2018;18:675. doi: 10.1186/s12889-018-55854.

39. Jamie K, O’Neill R, Bows H, Hackshaw-McGeagh L. Healthcare practitioner relationships, cultural health capital and breastfeeding support for adolescent mothers. Health Education J 2020;79:901-13. doi: 10.1177/001789692091594.
40. Sun K, Chen M, Yin Y, Wu L, Gao L. Why Chinese mothers stop breastfeeding: Mothers' selfreported reasons for stopping during the first six months. J Child Health Care 2017;21:353-63. Doi:10.1542/peds.2008-1315i

41. Hamid SBA, Zaidi NM. Predictors of prenatal breastfeeding self-efficacy in Malaysian women: a cross-sectional study. J Gizi Pangan 2020;15:5362. Doi:10.25182/jgp.2020.15.1.53-62.

42. Ogbo FA, Ezeh OK, Khanlari S, et al. Determinants of exclusive breastfeeding cessation in the early postnatal period among culturally and linguistically diverse (CALD). Nutrients 2019;11: 1611. doi: 10.3390/nu11071611.

43. McKinney ES, James SR, Murray SS, Nelson K, Ashwill J, editors. Maternal child nursing. $5^{\text {th }} \mathrm{ed}$. Elsevier Inc; 2018.

44. Mirghafourvand M, Kamalifard M, Ranjbar F, Gordani N. Relationship of breastfeeding selfefficacy with quality of life in Iranian breastfeeding mothers. J Mater Fetal Neonat Med 2018;31:2721-8. doi: 10.1080/14767058.2017. 1354368.

45. Erbaydar NP, Erbaydar T. Relationship between caesarean section and breastfeeding: evidence from the 2013 Turkey demographic and health survey. BMC Pregnancy Childbirth 2020;20:55. doi: 10.1186/s12884-020-2732-6.

46. Parker MG, Melvin P, Graham DA, et al. Timing of first milk expression to maximize breastfeeding continuation among mothers of very low-birthweight infants. Obstet Gynecol 2019; 133:1208-15. doi: 10.1097/AOG.0000000000003258.

47. Mohammadi F, Kiani A, Gholamzadeh S, Asadi Noghabi F, Sadeghi T. The factors affecting successful breast-feeding. Iranian J Neonatol 2018;9:73-82.Doi:10.22038/IJN.2018.24904.1322. 